\title{
Quality of Life, Sexual Functions and Urinary Incontinence After Hysterectomy in Hungarian Women
}

\author{
Márta Hock ${ }^{1}$, Szilvia Tóth ${ }^{2}$, Géza Hartmann ${ }^{3}$, Tamás Hartmann ${ }^{4}$, József Bódis ${ }^{5}$, János Garai $^{6}$ \\ ${ }^{1}$ Institute of Physiotherapy and Sport Sciences, Faculty of Health Sciences, University of Pécs, Pécs, Hungary \\ ${ }^{2}$ Department of Rehabilitation, St. Luke Hospital, Dombóvár, Hungary \\ ${ }^{3}$ Institute of Human Physiology, Faculty of Medicine, University of Pécs, Pécs, Hungary \\ ${ }^{4}$ Department of Obstetrics and Gynecology, Hospital of Mohács, Mohács, Hungary \\ ${ }^{5}$ Department of Obstetrics and Gynecology, Faculty of Medicine, University of Pécs, Pécs, Hungary \\ ${ }^{6}$ Institute of Pathophysiology and Gerontology, Faculty of Medicine, University of Pécs, Pécs, Hungary
}

Email address:

hock.marta@etk.pte.hu (M. Hock)

\section{To cite this article:}

Márta Hock, Szilvia Tóth, Géza Hartmann, Tamás Hartmann, József Bódis, János Garai. Quality of Life, Sexual Functions and Urinary Incontinence After Hysterectomy in Hungarian Women. American Journal of Health Research. Vol. 3, No. 6, 2015, pp. 393-398. doi: 10.11648/j.ajhr.20150306.23

\begin{abstract}
Objectives: The aim of the current study is to examine changes in sexual function, incontinence and quality of life after hysterectomy, with particular regard to different surgical methods of hysterectomy. Material and methods: A total number of 210 women with hysterectomy were asked to answer the questionnaire between 2011 and 2013; 164 of them accepted to cooperate. Twenty-one women were excluded from the study because of depression, thus the final number of participants was 143. In our retrospective study, patients were randomized by the snowball sampling (or chain referral sampling) method into three groups: having had 1total abdominal hysterectomy; 2. vaginal hysterectomy; or 3. subtotal abdominal hysterectomy (according to Crobach). Three questionnaires were used to collect quality of life data: 1. our own questionnaire on general health status, 2. the Short Form 36 questionnaire, and 3. a combination of shortened versions of the Lemack and Female Sexual Function Index. For the statistical analysis, Student's t-test and/or the Mann-Whitney U-test were used. The statistical analysis was performed by using SPSS 20.0.5 system. The significance level of $\mathrm{p} \leq 0.05$ was used. Results: The mean age of the vaginal total hysterectomy group, abdominal subtotal hysterectomy and abdominal total hysterectomy was 50.08 \pm 3.1 ; $45.47 \pm 2.5$ and $48.27 \pm 2.7$ years, respectively $(\mathrm{p}=0.203)$. Their average BMI was $26.88 \pm 3.45 \mathrm{~kg} / \mathrm{m}^{2}$. The average length of the postoperative period was $4.05 \pm 2.25$ years. Participants had a mean number of children 1.74/person; most of the participants were married (59.44\%), and had a college or university degree (37.6\%). There was no statistically significant difference in quality of life data between the subgroups. In the subgroup of women with vaginal hysterectomy, significantly higher incidence of pelvic pain was felt once in a while during sexual intercourse $(p=0.047)$, and there was a significantly higher incidence of urinary incontinence $(\mathrm{p}=0.023)$ as well. Conclusion: Types of hysterectomy did not significantly affect long term quality of life in general, but vaginal hysterectomy was more likely to affect sexual function and to increase the risk of incontinence when compared with abdominal hysterectomy.
\end{abstract}

Keywords: Hysterectomy, Incontinence, Quality of Life, Sexual Function

\section{Introduction}

Hysterectomy is one the most frequent types of gynaecological surgical interventions in both the European Union (EU) and the United States of America (USA). [1] In the United States, more than 600.000 and in Germany around 140.000 hysterectomies are performed each year. During the operation, the uterus is removed, either with or without the cervix, either by opening the abdominal wall or through the vagina. The uterus has important physiological functions in sexual life which may be altered after its partial or total removal. The existence or lack of the substantial sensory nerve supply of the cervix, and accordingly, the existence or lack of the tactile stimuli on sexual intercourse may have a significant effect on sexual function. In some studies, however, substantial pelvic organ dysfunction was found to be uncommon 
following either total or subtotal hysterectomy. This may be explained by the fact that most of the significant autonomic innervations are located in the middle and the lateral thirds of the sacral and cardinal ligaments that are mostly preserved during hysterectomies. [2] The short-term effects of hysterectomy are satisfactory on quality of life according to most studies. No other previous research has found significant difference either in the quality of life, or in sexual functions when different modes of hysterectomy (vaginal or abdominal) were compared. [3, 4] Hence the effects of the various hysterectomy techniques concerning sexual functions and quality of life still need to be clarified.

In previous studies, the risk for developing urinary incontinence in postmenopausal women who had undergone hysterectomy has been found to increase by the age of 60 years. $[5,6]$ Prospective controlled studies have found either no change or rather an improvement in continence status following hysterectomy. [7, 9] The neuroanatomical structure is supposed to suffer less damage if total hysterectomy is compared with the subtotal technique. Due to these reasons, the incidence of incontinence may also be lower with a minor displacement of the bladder. $[10,11]$ In a nationwide population-based cohort study in Sweden, the risk of developing stress incontinence that manifests after surgical management is the highest in the first 5 years following hysterectomy. [12] Acknowledged researchers of the field recommend further long-term clinical trials based on further studies.

The aim of our study was to monitor alterations in sexual function, the development of incontinence and changes in the quality of life following hysterectomy with special regard to a particular subtype of surgical methods, and it was assessed in subjects in the late postoperative period.

\section{Material and Methods}

It was a retrospective study, in which the snowball sampling method was used to select the subjects. The examination was performed between 2011 and 2013. Two hundred-ten subjects were involved from and around the cities of Pécs and Szekszárd, in the region of SouthTransdanubia, and they were contacted postoperatively. The women surveyed underwent total or subtotal and abdominal or vaginal hysterectomy. Exclusion criteria were as follows: depression, any neurological or psychiatric disease, abnormal cervical smears and endometriosis, and hysterectomy performed within 6 months. We did not ask patients about the exact reasons for hysterectomy or if anti-incontinence procedure was performed together with the hysterectomy. We asked the patients to sign whether a benign or malignant disease was the reason of their hysterectomy.

We did not exclude patients who were sexually inactive in the preoperative period if they were sexually active during the postoperative period. Inclusion criteria were the following: any kind of hysterectomy performed for benign indications within at least 6 months.

The questionnaires were mailed or personally delivered to the subjects with reply envelopes. The trial was approved by the local ethics committee (Reg. Nr: 4590). Each woman was informed about the experimental design of the study, and they gave their written informed consent to participate.

\section{Data Collection}

Three questionnaires were used for data collection: a selfcompiled demographic questionnaire $\left(1^{\mathrm{st}}\right)$, the Short Form (SF) 36 questionnaire $\left(2^{\text {nd }}\right)$, and a shortened combined version of the Lemack and Female Sexual Function Index (FSFI) questionnaire $\left(3^{\text {rd }}\right)$. The first questionnaire collected the following data on the patients: age, body weight, body height, education, occupation, number of children, their birth weight and method of birth, menopausal status, incontinence, previous gynaecological surgeries and their dates, comorbidities (if any), and the date of the hysterectomy.

The SF 36 questionnaire asked for the following questiongroups: physical functions (10 questions), role limitations (7 questions), energy/fatigue (4 questions), emotional wellbeing (5 questions), social function ( 2 questions), pain (2 questions) and general health condition (5 questions). [13] The main question-groups of the shortened version of the Lemack and FSFI were as follows: libido, vaginal dryness, orgasm, general satisfaction during sexual intercourse, the existence or lack of sexual life during the preoperative year, possibly the cause of the lack of sexual life, frequency, and painfulness. [14, 15] Due to issues relating to the sexual nature of the survey, it was completely anonymous. The overall number of the questions was 50 .

\section{Statistical Analysis}

Descriptive statistics were used for demographic and medical data and Chi-square tests for non-parametric variables. Mann-Whitney U-test and/or t-test were used for the statistical analysis. To investigate categorical variables, the Chi-square $\left(\chi^{2}\right)$ test was applied, and to compare categorical and continuous variables, the ANOVA test was used. Significance level was established at $p \leq 0.05$. All the calculations were performed with the SPSS software package (release 20.0.5; SPSS Inc, Chicago, USA).

\section{Results}

Of the 210 women asked to fill in the questionnaires, 164 were willing to participate in the study. Twenty-one of them were excluded either due to self-reported depression or returning questionnaires that were not fully assessable. The total number of subjects was 143 with a $78.09 \%$ answering rate.

\subsection{Demographic Data}

The mean age of the participants was $51.77 \pm 10.17$ years, and their average BMI was $26.88 \pm 3.45 \mathrm{~kg} / \mathrm{m}^{2}$. The average length of the postoperative period was $4.05 \pm 2.25$ years. The average number of children was 1.74 ; most of the participants were married $(59.44 \%)$ and had a college or university degree $(37.6 \%)$ (Table 1$)$. 
Table 1. Descriptive characteristic of patients $(n=143)$.

\begin{tabular}{llllllllll}
\hline \multirow{2}{*}{$\begin{array}{l}\text { General } \\
\text { information }\end{array}$} & \multicolumn{2}{l}{ Highest educational degree } & \multicolumn{3}{l}{ Number of children } & \multicolumn{2}{l}{ Marital status } \\
\cline { 2 - 11 } & $\begin{array}{l}\text { vocational } \\
\text { school }\end{array}$ & $\begin{array}{l}\text { secondary } \\
\text { school }\end{array}$ & university & childless & $\begin{array}{l}\text { one or two } \\
\text { children }\end{array}$ & $\begin{array}{l}\text { three or more } \\
\text { children }\end{array}$ & married & $\begin{array}{l}\text { living in } \\
\text { partnership }\end{array}$ & $\begin{array}{l}\text { divorced } \\
\text { or widow }\end{array}$ \\
\hline $\mathrm{n}$ & 40 & 50 & 53 & 20 & 91 & 32 & 85 & 45 & 13 \\
$\%$ & 27.97 & 34.96 & 37.06 & 13.99 & 63.63 & 22.38 & 59.44 & 31.45 & 9.08 \\
\hline
\end{tabular}

Seventeen females $(11.88 \%)$ had incontinence and $21.67 \%$ were sexually inactive (Figure 1).

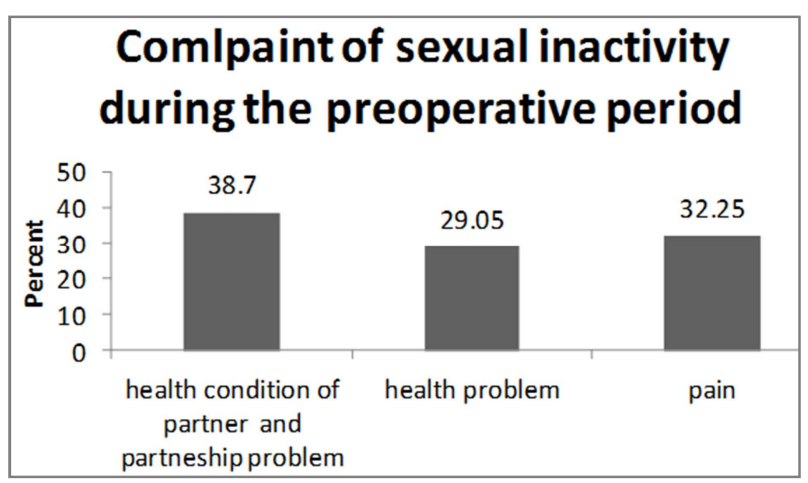

Figure 1. Reasons of sexual inactivity in preoperative period.

The number of subjects in the different subgroups based on the operation types is as follows: vaginal total hysterectomy group (VTH): 54 subjects (37.77\%), 38 subjects $(26.58 \%)$ in the abdominal subtotal hysterectomy group (ASH), and 51 subjects (35.66\%) in the abdominal total hysterectomy group (ATH). The age difference between the 3 groups was not significant $(\mathrm{p}=0.203)$. Prior to hysterectomy, 49 females had other surgical interventions due to gynaecological problems (34.26\%) (Table 2).

Table 2. Gynaecological data of surveyed group $(n=143)$.

\begin{tabular}{|c|c|c|c|c|c|c|}
\hline \multirow{2}{*}{$\begin{array}{l}\text { Types of } \\
\text { surgery }\end{array}$} & \multirow{2}{*}{$\mathbf{n}$} & \multirow{2}{*}{$\begin{array}{l}\text { age } \\
\text { years }\end{array}$} & \multicolumn{2}{|c|}{ previous operations } & \multicolumn{2}{|c|}{ postmenopause } \\
\hline & & & person & $\%$ & person & $\%$ \\
\hline VTH* & 54 & $50.08 \pm 3.1$ & 17 & 31.48 & 18 & 33.35 \\
\hline $\mathrm{ASH}^{0}$ & 38 & $45.47 \pm 2.5$ & 11 & 28.95 & 10 & 26.32 \\
\hline $\mathrm{ATH}^{+}$ & 51 & $48.27 \pm 2.7$ & 21 & 41.18 & 17 & 33.34 \\
\hline
\end{tabular}

Abbreviations: $*$ Vaginal total hysterectomy; ${ }^{0}$ Abdominal subtotal hysterectomy; ${ }^{+}$Abdominal total hysterectomy

\subsection{Life Quality}

Life quality was evaluated with the SF-36 questionnaire. The test involved seven question groups. There was no statistically significant difference found in either of the questionnaire subgroups between the subject groups in life quality (physical function, role limitation, energy/fatigue, emotional well-being, social function, pain, and general health) (Table 3).
Table 3. Statistical results ( $p$ value) of SF-36.

\begin{tabular}{llll}
\hline Question-groups & ATH $^{+}$ & ASH $^{\mathbf{0}}$ & VTH* $^{*}$ \\
\hline Physical functions & 0.246 & 0.684 & 0.332 \\
Role limitations & 0.566 & 0.441 & 0.078 \\
Energy/fatigue & 0.847 & 0.723 & 0.064 \\
Emotional well-being & 0.091 & 0.732 & 0.845 \\
Social function & 0.484 & 0.221 & 0.468 \\
Pain & 0.351 & 0.661 & 0.097 \\
General health condition & 0.123 & 0.082 & 0.747 \\
\hline \multirow{2}{*}{ Abbreviations: ${ }^{*}$ Vaginal } & \multirow{2}{*}{ total hysterectomy; ${ }^{0}$ Abdominal subtotal }
\end{tabular}

hysterectomy; ${ }^{+}$Abdominal total hysterectomy

\subsection{Sexual Function}

The questionnaire for measuring sexual function was compiled from the question groups of two questionnaires: the shortened version of the Lemack and the Female Sexual Function Index (FSFI). One of the major question groups of the questionnaire surveying sexual function was built on the questions of Lemack, who investigated sexual life during the preoperative period. Thirty one (21.67\%) subjects out of 143 indicated that they had been sexually inactive during the preoperative period. None of them remained inactive after the surgery. Two $(6.45 \%)$ of the preoperatively inactive subjects became very satisfied, 23 (74.19\%) moderately satisfied and $6(19.35 \%)$ slightly satisfied with their sexual life after the surgery.

From all the patients $(n=143), 68(47.55 \%)$. mentioned pain interfering with sexual life among the complaints 17 $(11.89 \%)$ of them belonged to the ones who were sexually inactive in the preoperative period. Although dissatisfaction was not reported, but minor complaints in sexual life did occur: thirty-five females complained of vaginal dryness (24.47\%), 34 patients mentioned lack of orgasm (23.77\%) and 69 females complained of decreased libido (48.25\%). None of the subject reported or experienced complaints that would significantly inhibit or hinder their sexual life. None of the women were dissatisfied with their general postoperative condition.

Concerning the 15 questions about the nine question groups (frequency and intensity of sexual desire, frequency and degree of sexual excitement, vaginal wetness, vaginal wetness till the end of intercourse, orgasm, general satisfaction with sexual life, and pain) chosen from the original FSFI question groups, there was no statistically significant difference $(p>0.05)$ found with regard to the three different modes of surgery. 
The analysis of the three different subgroups showed a significant difference at only one point. In the vaginal total hysterectomy group, the number of those who admitted to occasionally feeling pain during sexual activity was slightly higher $(p=0.047)$ than the number of those who admitted to rarely feeling pain during sexual activity (Table 4).

Table 4. The pain and incontinence distribution by subtypes of hysterectomy.

\begin{tabular}{|c|c|c|c|c|c|c|c|c|c|c|c|c|c|}
\hline \multirow{3}{*}{$\begin{array}{l}\text { Types of } \\
\text { surgery }\end{array}$} & \multicolumn{10}{|c|}{ pain } & \multirow{2}{*}{\multicolumn{2}{|c|}{ incontinence }} & \multirow{3}{*}{ p value } \\
\hline & \multicolumn{4}{|c|}{ quality of life } & \multirow{2}{*}{$\begin{array}{l}\text { scores p } \\
\text { value }\end{array}$} & \multicolumn{4}{|c|}{ sexual function } & \multirow{2}{*}{ scores $p$ value } & & & \\
\hline & $\mathbf{n}$ & $\%$ & scores & SD & & $\mathbf{n}$ & $\%$ & scores & SD & & $\mathbf{n}$ & $\%$ & \\
\hline $\mathrm{ATH}^{+}$ & 23 & 45.11 & 2.29 & \pm 1.48 & 0.732 & 21 & 41.18 & 1.88 & \pm 0.19 & 0.446 & 12 & 23.54 & 0.784 \\
\hline $\mathrm{ASH}^{0}$ & 20 & 52.64 & 2.53 & \pm 1.46 & 0.521 & 18 & 47.37 & 1.93 & \pm 0.33 & 0.578 & 6 & 15.67 & 0.321 \\
\hline VTH* & 15 & 27.78 & 2.22 & \pm 1.13 & 0.641 & 29 & 53.71 & 1.99 & \pm 0.48 & 0.074 & 16 & 29.65 & 0.023 \\
\hline
\end{tabular}

Abbreviations:*Vaginal total hysterectomy; ${ }^{0}$ Abdominal subtotal hysterectomy; ${ }^{+}$Abdominal total hysterectomy

\subsection{Incontinence}

Incontinence was reported in 34 cases $(23.77 \%)$. Nineteen subjects had stress incontinence, and 15 females experienced urge incontinence. Six subjects (17.64\%) noticed urine loss during sexual intercourse. When comparing the 3 groups, the vaginal total hysterectomy group showed a significantly increased involuntary loss of urine $(\mathrm{p}=0.023)$ (Table 4).

\section{Discussion}

The answering rate in the present study is considered to be considerably high. One-fourth of the women were sexually inactive before surgery, but none of these patients were inactive and significantly dissatisfied with their sexual function after the intervention. According to certain previous findings, the effects of the subtypes of hysterectomy on sexual function were statistically not significant. No significant difference was found between subtotal and total techniques in recent studies. Earlier studies have reported that hysterectomy improves female sexual function. $[4,16]$ The physiological background of human female sexual functioning is rather complex. The independent role of the uterus or the cervix has not been established beyond doubt so far by scientific studies. [17] According to our study, the removal of the cervix itself had no adverse effect on sexuality. The only one characteristic of sexual function that was found different between the groups was the increased rate of occasional pain during intercourse in the TVH group. When findings related to life quality in general were also taken into consideration, the lowest scores of pain could be found in the vaginal total hysterectomy group. This may point to the possibility that pain during sexual intercourse could originate from nearby structures the genitourinary tract but not necessarily or solely from the genitourinary tract. It is known that adhesions can also cause a similar problem but mainly attributed to abdominal surgeries. [18, 19] The posthysterectomy vaginal pain in the VTH group may result from the scarring process of the vaginal wall, as it has also been proposed by previous papers. We should remember, however, that the average age in the VTH group was higher than in the other groups. More advanced age was previously found to correlate with greater pain as it has been reported in connection with the sexual act. $[20,21]$ The topic is rather varied due to the complex nature of the subject itself. The multitude of the anatomical and other aspects of sexual function, such as emotional well-being, partnership intimacy, life quality, physical health and the complicating conditions (myoma, bleeding disorders, or pelvic organ prolapse), combined with the various surgical interventions necessary (hysterectomy and various anti-incontinence techniques) will result in varied outcomes. [22] The time factor must also be taken into account, as findings during the first six months after hysterectomy may show the presence of adverse effects. [23] Other findings suggest that there is no significant change compared with the preoperative condition. Yet another report has concluded that deterioration in sexual life may not be attributed solely to the surgical intervention. [24, 25] Hence the effects of the various hysterectomy techniques concerning sexual functions still need to be clarified.

According to our findings, the subtypes of hysterectomy have no significantly different effects on quality of life. Former findings have shown that significant improvement in life quality could be observed during the first year after the surgery, although the EuroQol (EQ-5D) questionnaire has been used in that study. [26] In our case, the average time from surgery was three years longer than that in that research. The longer time interval involved allows for the possibility that it is not only the eliminated negative symptoms, such as the presence or absence of disorders that determine the reported quality of life. Apart from the negative symptoms, getting rid of their source, i.e. removal of the uterus, does not seem to be a major determinant of life quality in the long term. Subtypes of hysterectomy did not affect long term quality of life significantly.

The association or causality (if any) between hysterectomy and subsequent urinary incontinence is not fully established yet because of the apparent lack of firm, data-based evidence. Physician's experience, nevertheless, shows that there might be a correlation.

During hysterectomy, the pelvic plexus may be at risk of injury at the division of the cardinal ligaments, at the blunt dissection of the bladder from the uterus, at the dissection of the paravaginal tissue, and at the removal of the cervix. [27, 28] The pelvic floor muscles as well as urethral and anal sphincters are also innervated by distal branches of the pudendal nerves. Damage to the distal branches of the 
pudendal nerves and the inferior hypogastric plexus may disturb the urethral sphincter closing mechanism. This may lead to the development of incontinence. After hysterectomy the changes of the anatomy and innervation may also cause subsequent changes in urethral pressure dynamics and bladder neck support, resulting in failure of the urethral function. [5] Some studies have shown that previous hysterectomy does not seem to be of great importance in the development of de novo incontinence. [11] In other studies, hysterectomy for benign indications seems to increase the risk frequency subsequent stress urinary incontinence. [6] In 2000 Brown described the increasing effect of total hysterectomy techniques on incontinence in a systematic review. [5] This has been confirmed by Roovers et al. (2001) in connection with urge incontinence after vaginal hysterectomy, and similar results have been obtained by Gimbel, although they directed attention to the higher risk of the subtotal technique. [29,30] According to Lakeman et al., lower urinary tract symptoms appear to be more common following vaginal hysterectomy as compared to abdominal hysterectomy. [31] On the basis of our findings, the incidence of incontinence in the total vaginal group is also significantly higher. Further studies are warranted on account of the importance, complexity and unsettled nature of these issues.

The limitations of our study are the relatively low case number, and the non-randomized and non-double-blind sampling. A significant number of the patients were not contacted directly in person but via the questionnaire that was delivered by mail. The questionnaires were selfadministered. Our basic questionnaire (Lemack / FSFI) was shortened to improve the willingness of the subjects to give answers. The number of questions was also minimized to promote cooperation. Our questions on preoperative status were also minimized, hence, for example, the existence of triggering factors for incontinence was not asked for. We did not collect information on whether the participants used any nonsurgical treatment, such as pelvic floor exercise or intravaginal devices for the improvement of their continence.

Due to the high number of women affected by this intervention, we hope that our findings will stimulate further research in order to solve issues that are currently unclear.

Clinical findings: Our results indicate that in the long term none of the subtypes of hysterectomy have a significant adverse effect on the quality of life. After examining the patient, during the clinical decision-making, it may be worth considering that the incidence of incontinence may be more prevalent after vaginal hysterectomy. The patient should be informed that the effect different hysterectomy subtypes have on sexual function is still unclear.

\section{Conclusions}

Hysterectomy did not significantly affect the long term quality of life in general, but vaginal hysterectomy was more likely to affect sexual function and increase the risk of incontinence when compared with abdominal hysterectomy.

\section{References}

[1] Whiteman MK, Hillis SD, Jamieson DJ, et al. Inpatient hysterectomy surveillance in the United States, 2000-2004. Am J Obstet Gynecol 2008; 198: 34.e1-7.

[2] Butler-Manuel SA, Buttery LDK, A'Hern RP, Polak JM, Barton DPJ. Pelvic nerve plexus trauma at radical and simple hysterectomy: the nerve content of the uterine supporting ligaments. Cancer 2000; 89(4): 834-841.

[3] Roovers JP, van der Bom JG, van der Vaart CH, Heintz AP. Hysterectomy and sexual wellbeing: prospective observational study of vaginal hysterectomy, subtotal abdominal hysterectomy, and total abdominal hysterectomy. BMJ 2003; 327(7418): 774-778.

[4] Roussis NP, Waltrous L, Kerr A, Robertazzi R, Cabbad MF. Sexual response in the patient after hysterectomy: Total abdominal versus supracervical versus vaginal procedure. Am J Obstet Gynecol 2004; 190(5): 1427-8.

[5] Brown JS, Sawaya G, Thom DH, Grady D. Hysterectomy and urinary incontinence: a systematic review. Lancet 2000; 356(9229): 535-539.

[6] Kudish BI, Shveiky D, Gutman RE, et al. Hysterectomy and urinary incontinence in postmenopausal women. Int Urogynecol J 2014; 25(11): 1523-31.

[7] de Tayrac R, Chevailer N, Chauveaud-Lambling A, Gervaise A, Fernandez H. Risk of urge and stress urinary incontinence at long term follow up after vaginal hysterectomy. Am J Obstet Gynecol 2004; 191(1): 90-94.

[8] Kjerulff KH, Langenberg PW, Greenaway LV, Uman J, Harvey LA. Urinary incontinence and hysterectomy in a large prospective cohort study in American women. J Urol 2002; 167(5): 2088-2092.

[9] Vierhout ME. Influence of nonradical hysterectomy on the function of the lower urinary tract. Obstet Gynecol Surv 2001; 56(6): 381-386.

[10] Thakar R, Ayers S, Clarkson P, Stanton S, Manyonda I. Outcomes After Total Versus Subtotal Abdominal Hysterectomy. N Engl J Med 2002; 347(17): 1318-25.

[11] Greer WJ, Richter HE, Wheeler TL, et al. Long-Term Outcomes of the Total or Supracervical Hysterectomy (TOSH) Trial. Female Pelvic Med Reconstr Surg 2010; 16(1): 49-57.

[12] Altman D, Granath F, Cnattingius S, Falconer C. Hysterectomy and risk of stress-urinary-incontinence surgery: nationwide cohort study. Lancet 2007; 370(9597): 1494-1499.

[13] McHorney CA, Ware JE, Raczek AE. The MOS 36-Item Short-Form Health Survey (SF-36): II. A psychometric and clinical test of validity in measuring physical and mental health constructs. Med Car 1993; 31(3): 247-63.

[14] Lemack GE, Zimmern PE. Sexual function after vaginal surgery for stress incontinence: results of a mailed Questionnaire. Urology 2000; 56(2): 223-7.

[15] Rosen R, Brown C, Heiman J, et al. The Female Sexual Function Index (FSFI): a multidimensional self-report instrument for the assessment of female sexual function. J Sex Marital Ther 2000; 26(2): 191-208. 
[16] Ghielmetti T, Kuhn P, Dreher EF, Kuhn A. Gynecological operations: Do they improve sexual life? Eur J Obstet Gynecol Reprod Biol 2006; 129(2): 104-110.

[17] Hasson HM. Cervical removal at hysterectomy for benign disease: risks and benefits. J Reprod Med 1993; 38(10): 781790 .

[18] Parker WH. Laparoscopic myomectomy and abdominal myomectomy. Clin Obstet Gynaecol 2006; 49(4): 789-797.

[19] Polish Gynecological Society. Polish gynecological society consensus in adhesion reduction management. Ginekol Pol 2010; 81(3): 235-236.

[20] Komisaruk BR, Frangos E, Whipple B. Hysterectomy improves sexual response? Addressing a crucial omission in the literature. J Minim Invasive Gynecol 2011 May-Jun; 18(3): 288-95. doi: 10.1016/j.jmig.2011.01.012.

[21] Ratner ES, Erekson EA, Minkin MJ, Foran-Tuller KA. Sexual satisfaction in the elderly female population: A special focus on women with gynecologic pathology. Maturitas 2011 Nov; 70(3): 210-5. doi: 10.1016/j.maturitas.2011.07.015. Epub 2011 Sep 22.

[22] Tunuguntla HS, Gousse AE. Female Sexual Dysfunction Following Vaginal Surgery: A Review. J Urol 2006; 175(2): 439-446.

[23] Celik H, Gurates B, Yavuz A, Nurkalem C, Hanay F, Kavak B. The effect of hysterectomy and bilaterally salpingooophorectomy on sexual function in post-menopausal women. Maturitas 2008; 61(4): 358-363.
[24] Ambler DR, Bieber EJ, Diamond MP. Sexual function in elderly women: a review of current literature. Rev Obstet Gynecol 2012; 5(1): 16-27.

[25] Ryann Louie A, Armstrong JA, Findeiss LK, Goodwin SC. Comparison of Sexual Dysfunction Using the Female Sexual Function Index following Surgical Treatments for Uterine Fibroids. Case Rep Obstet Gynecol 2012; 2012:368136. doi: 10.1155/2012/368136. Epub 2012 Aug 23.

[26] Gorlero F, Lijoi D, Biamonti M, et al. Hysterectomy and women satisfaction: total versus subtotal technique. Arch Gynecol Obstet 2008; 278(5): 405-410.

[27] Smith PH, Ballantyne B. The neuroanatomical basis for denervation of the urinary bladder following major pelvic surgery. Br J Surg 1968; 55(12): 929-933.

[28] Mokate T, Wright C, Mander T. Hysterectomy and sexual function. J Br Menopause Soc 2006; 12(4): 153-157.

[29] Roovers JP, van der Bom JG, Huub van der Vaart C, Fousert DM, Heintz AP. Does mode of hysterectomy influence micturition and defecation? Acta Obstet Gynecol Scand 2001; 80(10): 945-51.

[30] Gimbel H. Total or subtotal hysterectomy for benign uterine diseases? A meta-analysis. Acta Obstet Gynecol Scand 2007; 86(2): 133-144.

[31] Lakeman MM, van der Vaart CH, Roovers JP. Hysterectomy and Lower Urinary Tract Symptoms: A Nonrandomized Comparison of Vaginal and Abdominal Hysterectomy on behalf of the HysVA study group. Gynecol Obstet Invest 2010; 70(2): 100-106. 